\title{
Observed and Expected Survival in Men and Women after Suffering a STEMI
}

\author{
Isaac Pascual 1,2,3, Daniel Hernandez-Vaquero 2,3,4,*(D), Marcel Almendarez ${ }^{1} \mathbb{D}$, Rebeca Lorca ${ }^{1,2}$, \\ Alain Escalera ${ }^{4}$, Rocío Díaz ${ }^{2,4}$, Alberto Alperi ${ }^{1}$ (D), Manuel Carnero ${ }^{5}$, Jacobo Silva ${ }^{4,6}$, \\ Cesar Morís 1,2,7 (D) and Pablo Avanzas 1,2,7 (D) \\ 1 Department of Cardiology, Central University Hospital of Asturias, 33011 Oviedo, Spain; \\ ipascua@live.com (I.P.); marcel.almendarez@gmail.com (M.A.); lorcarebeca@hotmail.com (R.L.); \\ alberto.alperi.garcia@hotmail.com (A.A.); cesarmoris@gmail.com (C.M.); avanzas@gmail.com (P.A.) \\ Research Institute of the Principado de Asturias, 33011 Oviedo, Spain; diazmendezro@gmail.com \\ 3 Department of Functional Biology, Physiology Area, Faculty of Medicine, University of Oviedo, \\ 33006 Oviedo, Spain \\ 4 Cardiac Surgery Department, Central University Hospital of Asturias, 33011 Oviedo, Spain; \\ alain_2623@hotmail.com (A.E.); jsilva8252@yahoo.es (J.S.) \\ 5 Cardiac Surgery Department, San Carlos Clinic Hospital, 28040 Madrid, Spain; mcarnero@me.com \\ 6 Department of Surgery, Faculty of Medicine, University of Oviedo, 33006 Oviedo, Spain \\ 7 Department of Medicine, Faculty of Medicine, University of Oviedo, 33006 Oviedo, Spain \\ * Correspondence: dhvaquero@gmail.com
}

Received: 25 March 2020; Accepted: 17 April 2020; Published: 19 April 2020

\begin{abstract}
Introduction: Mortality caused by ST elevation myocardial infarction (STEMI) has declined because of greater use of primary percutaneous coronary intervention (PCI). It is unknown if patients $>75$ have similar survival as peers. We aim to know it stratifying by sex and assessing how the sex may impact the survival. Methods: We retrospectively selected all patients $>75$ who suffered a STEMI treated with primary $\mathrm{PCI}$ at our institution. We compared their survival with that of the reference population (general population matched by age, sex, and geographical region). A Cox-regression analysis controlling for clinical factors was performed to know if sex was a risk factor. Results: Total of 450 patients were studied. Survival at 1,3, and 5 years of follow-up for patients who survived the first 30 days was $91.22 \%$ (CI95\% 87.80-93.72), 79.71\% (CI95\% 74.58-83.92), and 68.02\% (CI95\% $60.66-74.3)$, whereas in the reference population it was $93.11 \%, 79.10 \%$, and $65.01 \%$, respectively. Sex was not a risk factor, Hazard Ratio $=1.02($ CI95\% 0.67-1.53; $p=0.92)$. Conclusions: Life expectancy of patients suffering a STEMI is nowadays intimately linked to survival in the first 30 days. After one year, the risk of death for both men and women seems similar to that of the general population.
\end{abstract}

Keywords: myocardial infarction; life expectancy; gender

\section{Introduction}

Ischemic heart disease is the single most common cause of death worldwide and its prevalence is increasing, with variations between countries [1].

Short and long-term mortality caused by ST elevation myocardial infarction (STEMI) has significantly declined during past decades because of greater use of primary percutaneous coronary intervention (PCI), modern antithrombotic therapy, and secondary prevention measures $[1,2]$. Nevertheless, mortality remains high. In-hospital mortality of unselected patients with STEMI ranges from 4 to $12 \%$. Mortality at one-year follow-up is approximately $10 \%$ [3,4]. Primary PCI has widely shown to be a life-saving procedure in the STEMI setting. However, several factors have an impact on 
mortality just after the STEMI. Age, sex, left ventricular function, or reperfusion therapy have been previously identified [1-4].

Age is an unmodifiable risk factor for mortality. It is known that patients $>75$ years old, even those treated with primary PCI, are at a higher risk of death. However, it is unknown whether this subgroup of patients may recover their life expectancy. Some studies have described long-term survival of patients with STEMI treated with primary PCI [3,5]. However, these results alone provide little information because the life expectancy of any population depends on the region of residence. In fact, there are significant differences in mortality even between industrialized countries. For instance, women 65 years of age have a life expectance 2 years longer in Spain than in the United States [6].

Moreover, sex is one of the key factors affecting the frequency and severity of acute myocardial infarction (MI). Several studies have shown a later onset of MI in women compared with men. Thus, MI occurs more often in men below 60 years and in women above 75 years [7-10]. A significant relationship between sex and age after acute MI has been demonstrated. On one hand, young women may have higher mortality than young men. On the other, mortality between both sexes seems similar in the elderly population [11,12]. In women, MI appears more frequently with atypical symptoms, which can delay primary PCI. In addition, the risk of bleeding during PCI and the presence of comorbidities in this group are higher and may have an impact on survival [13-15]. In this regard, previous works have shown that women with STEMI have higher short-term mortality than men $[16,17]$.

However, there is an active debate regarding whether long-term survival could be worse in women. In many countries and geographical areas of the world, women have higher life expectancy than men. Therefore, comparing long-term survival curves in men and women after a STEMI would be insufficient [18-21]. The main objective of this study is to analyze whether patients $>75$ years of age with STEMI treated with primary PCI recover a life expectancy similar to that of the general population for the same age, sex, and geographical area, focusing on differences between sexes.

\section{Material and Methods}

\subsection{Selection of the STEMI Sample and Construction of the Reference Population}

We retrospectively selected all consecutive patients older than 75 years old suffering STEMI treated with primary PCI, from January 2014 to January 2020 at the Hospital Universitario Central of Asturias, in Spain. The primary PCI was performed for all patients who fulfilled the definition of STEMI following the ESC guidelines. This was defined as emergent PCI with balloon, stent or another approved device performed on the infarct-related artery without fibrinolytic treatment [1]. All procedures were performed in a catheterization laboratory by the same team of senior interventional cardiologists with more than 10 years of experience in primary PCI.

The reference population was constructed using mortality data of our Autonomous Region (Principality of Asturias) from the Spanish National Institute of Statistics (INE) stratified by age and sex. These data are available on the official INE website (http://www.ine.es/jaxiT3/Tabla.htm? $t=27154$ ). In order to be able to compare their late survival with that of the general population, all patients were matched by age and sex with the general population of the same geographical area. The whole process is described in the statistical section.

\subsection{Data Collection}

We retrospectively collected all data related to the baseline, intra-procedural, short-, and long-term follow-up periods from a digital database. One of the researchers collected all-cause mortality data during the follow-up by analyzing the information available in the medical records of the Hospital Universitario Central of Asturias.

Usually, patients were treated at discharge following the optimal medical treatment according to European Society of Cardiology Guidelines [1]. 


\subsection{Primary Objectives}

1. To compare the survival curves of patients with STEMI treated with primary PCI with that of the general population, matching by age, sex, and geographical region.

2. To compare the survival curves of patients who survive hospital discharge or first 30 days after the STEMI with that of the general population matching by age, sex, and geographical region.

3. To establish differences between men and women in the previous objectives.

4. To know if sex is a risk factor for long-term mortality.

\subsection{Statistical Analysis}

Quantitative and categorical variables were described as mean \pm standard deviation (SD) and $n$ (\%), respectively. To compare survival of patients who suffered a STEMI with the general population of the same sex, age, and territory, we calculated the following estimations: (1) observed survival, (2) expected survival, and (3) relative survival (RS) [22-24]. The "strs" command of STATA ${ }^{\circledR}$ v.15.1 (College Station, TX, USA) was used [25].

1. Observed survival is the real survival of the patients who suffered a STEMI and were treated by primary PCI at our institution. To estimate it, the usual Kaplan-Meier analysis was used.

2. Expected survival is considered the estimated life expectancy of a person from our region matched for the same characteristics (age and sex) of our STEMI patient. In other words, the theoretical survival of the patients if they had not suffered the STEMI. Its calculation was performed using the Ederer II method, which is the method of choice for the matching [26]. This method uses the mortality rates for different intervals of age, sex, and region provided by the INE [27]. If the expected survival is included in the $95 \%$ confidence interval of the observed survival, no differences were considered to exist.

3. Relative survival is an estimation of the survival that patients would have in the theoretical assumption that they could only die due to that STEMI or its consequences $[25,28]$. Its calculation is derived from the rate between the observed survival and the expected survival. For instance, a RS of $100 \%$ would indicate that the STEMI had no consequences on survival. Conversely, a RS of $80 \%$ during the first year would indicate that $20 \%(100-80 \%)$ of the patients who suffered the STEMI died because of this event or any of its consequences [22-24]. Therefore, if the confidence interval of the RS includes $100 \%$, there is no evidence of mortality due to the STEMI and this would indicate that the primary PCI was completely effective in solving the problem $[26,28]$.

In order to further study the influence of sex on late survival, a Cox regression analysis was performed. Sex was considered the independent variable and the following variables acted, from a theoretical point of view, as possible confounding factors: age, diabetes, hypertension, dyslipidemia, history of smoking, chronic renal dysfunction, previous acute myocardial infarction, previous coronary surgery, previous coronary angioplasty, lesion on anterior descending artery, multivessel disease, and Killip class 3 or 4 . Hazard proportionality was evaluated by visual assessment of the $\ln$ (analysis of time) vs. - $\ln$ (-ln survival probability). The role of sex on late survival was evaluated taking into account the risk of being woman versus being a man (reference). A $p$ value $<0,05$ was considered statistically significant. All analyses were performed with STATA ${ }^{\circledR}$ v.15.1 (STATA Corp, TX, USA). This study was conducted in accordance with the Declaration of Helsinki.

\section{Results}

\subsection{Baseline Characteristics}

During the study period, we included 450 consecutive patients with a STEMI, treated with primary PCI. Total of 438 patients out of 450 were Caucasian (97.3\%); 263 (58.4\%) patients were male. Female patients were slightly older ( 83.1 vs. 81.6 years old), with higher prevalence of hypertension and lower 
prevalence of smoking habit, previous MI and previous CABG. The rest of the baseline characteristics had no significant differences (Table 1).

Table 1. Baseline characteristics.

\begin{tabular}{cccc}
\hline Variable & Male $(\boldsymbol{n = 2 6 3 )}$ & Female $(\boldsymbol{n = 1 8 7 )}$ & $p$ \\
\hline Age (Years) & $81.6 \pm 4.7$ & $83.1 \pm 4.8$ & 0.001 \\
Hypertension & $152(57.8 \%)$ & $132(70.6 \%)$ & 0.005 \\
Diabetes & $84(31.9 \%)$ & $52(27.8 \%)$ & 0.347 \\
Dyslipidemia & $116(44.1 \%)$ & $69(36.8 \%)$ & 0.126 \\
Smoking Habit & $117(44.5 \%)$ & $18(9.6 \%)$ & 0.001 \\
Chronic Kidney Disease & $38(14.4 \%)$ & $24(12.8 \%)$ & 0.624 \\
Previous Myocardial & $54(20.5 \%)$ & $22(11.8 \%)$ & 0.014 \\
Infarction & $39(14.8 \%)$ & $18(9.7 \%)$ & 0.102 \\
Previous PCI & $12(4.6 \%)$ & $0(0 \%)$ & 0.003 \\
Previous CABG & &
\end{tabular}

MI: myocardial infarction, PCI: percutaneous coronary intervention, CABG: coronary artery bypass grafting.

\subsection{Procedure and Discharge Data}

Radial approach was preferred with a similar distribution between men and women. The most frequent vessel affected was the left anterior descending artery in 218 patients $(48.4 \%)$ followed by the right coronary artery in 136 patients (30.2\%). Total of $308(68.4 \%)$ patients were in Killip class I followed by $70(15.6 \%)$ in class II (16.8\%). Male patients had more multivessel disease $141(53.6 \%)$ vs. $72(38.5 \%)$ in women. Total of $38(8.4 \%)$ of the patients had intra-procedural complications, $2(0.4 \%)$ patients had vascular complications, $25(5.6 \%)$ arrhythmic complications, $11(2.4 \%)$ required mechanical ventilation, and $7(1.6 \%)$ died during the procedure. At discharge, the mean LVEF was $49 \pm 11 \%$ and $80(17.8 \%)$ patients had a moderate or severe valvular heart disease (mitral or aortic). The peak ultra-sensitive troponin T was $5725( \pm 7410) \mathrm{pg} / \mathrm{mL}, 101(24.2 \%)$ patients developed contrast induced acute kidney injury and there were $59(13.1 \%)$ deaths during the admission or first 30 days. Detailed procedural and discharge data can be seen in Tables 2 and 3.

\subsection{Observed Survival, Expected Survival, and Relative Survival}

The mean of the follow-up of the censored observations was $34.6 \pm 21.4$ months. Overall, there were $141(31.3 \%)$ deaths, $86(32.7 \%)$ were men and $55(29.9 \%)$ were women. There were $31(11.8 \%)$ and $28(15.2 \%)$ deaths during the first 30 days after the STEMI in men and women respectively. All causes of death are described in Table 3.

Cumulative survival of patients with STEMI at 1, 3, and 5 years of follow-up was $81.56 \%$ (CI 95\% 77.51-84.96), 71.27\% (CI 95\% 66.21-75.72), and 60.82\% (CI 95\% 54.09-66.88), being 93.11\%, 79.10\%, and $65.01 \%$ respectively for the reference population. Figure 1 shows survival of patients who suffered a STEMI treated with primary PCI compared with the reference group.

Stratifying by sex, survival of men with STEMI at 1, 3, and 5 years of follow-up was $82.39 \%$ (CI 95\% 77.05-86.59), 69.71\% (CI 95\% 62.95-75.48\%), and 60.26\% (CI 95\% 51.97-67.58\%), whereas in the reference group was $92.51 \%, 76.86 \%$, and $62.06 \%$. Survival of women with STEMI at 1,3 , and 5 years of follow-up was $80.44 \%$ (CI 95\% 73.60-85.62\%), 74\% (CI 95\% 66.04-80.37), and 61.57\% (CI 95\% 49.24-71.74), whereas in the reference group it was $94.06 \%, 82.81 \%$, and $70.27 \%$. Figure 2 shows observed and expected survival stratified by sex. 
Table 2. Intra-procedural characteristics.

\begin{tabular}{|c|c|c|c|}
\hline Variable & Male $(n=263)$ & Female $(n=187)$ & $p$ \\
\hline \multicolumn{4}{|l|}{ Access: } \\
\hline Femoral & $113(42.9 \%)$ & $81(42.8 \%)$ & \multirow{3}{*}{0.894} \\
\hline Radial & $148(56.3 \%)$ & $106(56.7 \%)$ & \\
\hline Braquial & $2(0.8 \%)$ & $0(0 \%)$ & \\
\hline \multicolumn{4}{|l|}{ Culprit Artery: } \\
\hline Left Main & $13(4.9 \%)$ & $3(1.6 \%)$ & \multirow{5}{*}{0.147} \\
\hline LAD & $132(50.2 \%)$ & $86(46 \%)$ & \\
\hline LCX & $39(14.8 \%)$ & $37(19.8 \%)$ & \\
\hline RCA & $75(28.5 \%)$ & $61(32.6 \%)$ & \\
\hline Graft & $4(1.5 \%)$ & $0(0 \%)$ & \\
\hline Multivessel Disease & $141(53.6 \%)$ & $72(38.5 \%)$ & 0.002 \\
\hline Stents Implanted & $1.3 \pm 0.8$ & $1.3 \pm 0.9$ & 0.501 \\
\hline IABP & $14(5.3 \%)$ & $11(5.9 \%)$ & 0.799 \\
\hline Failed PCI & $11(4.2 \%)$ & $8(4.3 \%)$ & 0.960 \\
\hline \multicolumn{4}{|l|}{ Killip Kimball Class } \\
\hline $\mathrm{I}$ & $182(69.2 \%)$ & $126(67.4 \%)$ & \multirow{4}{*}{0.684} \\
\hline II & $39(14.8 \%)$ & $31(16.6 \%)$ & \\
\hline III & $16(6.1 \%)$ & $8(4.3 \%)$ & \\
\hline IV & $26(9.9 \%)$ & $22(11.8 \%)$ & \\
\hline Vascular Complications & $4(1.5 \%)$ & $5(2.7 \%)$ & 0.389 \\
\hline Arrhythmia & $15(5.7 \%)$ & $10(5.3 \%)$ & 0.871 \\
\hline Endotracheal Intubation & $4(1.5 \%)$ & $7(3.7 \%)$ & 0.132 \\
\hline US TnT (pg/mL) & $6175 \pm 547$ & $5112 \pm 507$ & 0.169 \\
\hline LVEF at Discharge & $48.93 \pm 11.3$ & $49.56 \pm 11.5$ & 0.584 \\
\hline CI-AKI & $61(23.2 \%)$ & $48(25.7 \%)$ & 0.546 \\
\hline Procedural Death & $3(1.1 . \%)$ & $4(2.1 \%)$ & 0.399 \\
\hline
\end{tabular}

LAD: left anterior descending coronary artery. LCX: left circumflex coronary artery. RCA: right coronary artery. IABP: intra-aortic balloon pump. PCI: percutaneous coronary intervention. US TnT: ultra-sensitive troponin T. LVEF: left ventricle ejection fraction. CI-AKI: contrast-induced acute kidney injury.

Table 3. Causes of death.

\begin{tabular}{ccc}
\hline Variable & & \\
\hline Deaths $<$ 30 days $(\boldsymbol{n}=\mathbf{5 9 )}$ & Male $(\boldsymbol{n = 3 1 )}$ & Female $(\boldsymbol{n}=\mathbf{2 8 )})$ \\
Cardiovascular & $25(80.7 \%)$ & $25(89.3 \%)$ \\
Stroke & $0(0 \%)$ & $1(3.6 \%)$ \\
Major Bleeding & $0(0 \%)$ & $0(0 \%)$ \\
Infection & $1(3.2 \%)$ & $0(0 \%)$ \\
Others & $5(16.1 \%)$ & $2(7.1 \%)$ \\
Deaths after Discharge or $>\mathbf{3 0}$ & Male $(n=55)$ & Female $(n=27)$ \\
days $(n=82)$ & $16(29.1 \%)$ & $11(40.7 \%)$ \\
Cardiovascular & $4(7.2 \%)$ & $4(14.8 \%)$ \\
Stroke & $0(0 \%)$ & $1(3.7 \%)$ \\
Major Bleeding & $6(10.9 \%)$ & $2(7.4 \%)$ \\
Sepsis & $6(10.9 \%)$ & $2(7.4 \%)$ \\
Respiratory Infection & $5(9.1 \%)$ & $2(7.4 \%)$ \\
Cancer & $5(9.1 \%)$ & $1(3.7 \%)$ \\
Unknown & $13(23.6 \%)$ & $4(14.8 \%)$ \\
Others & &
\end{tabular}




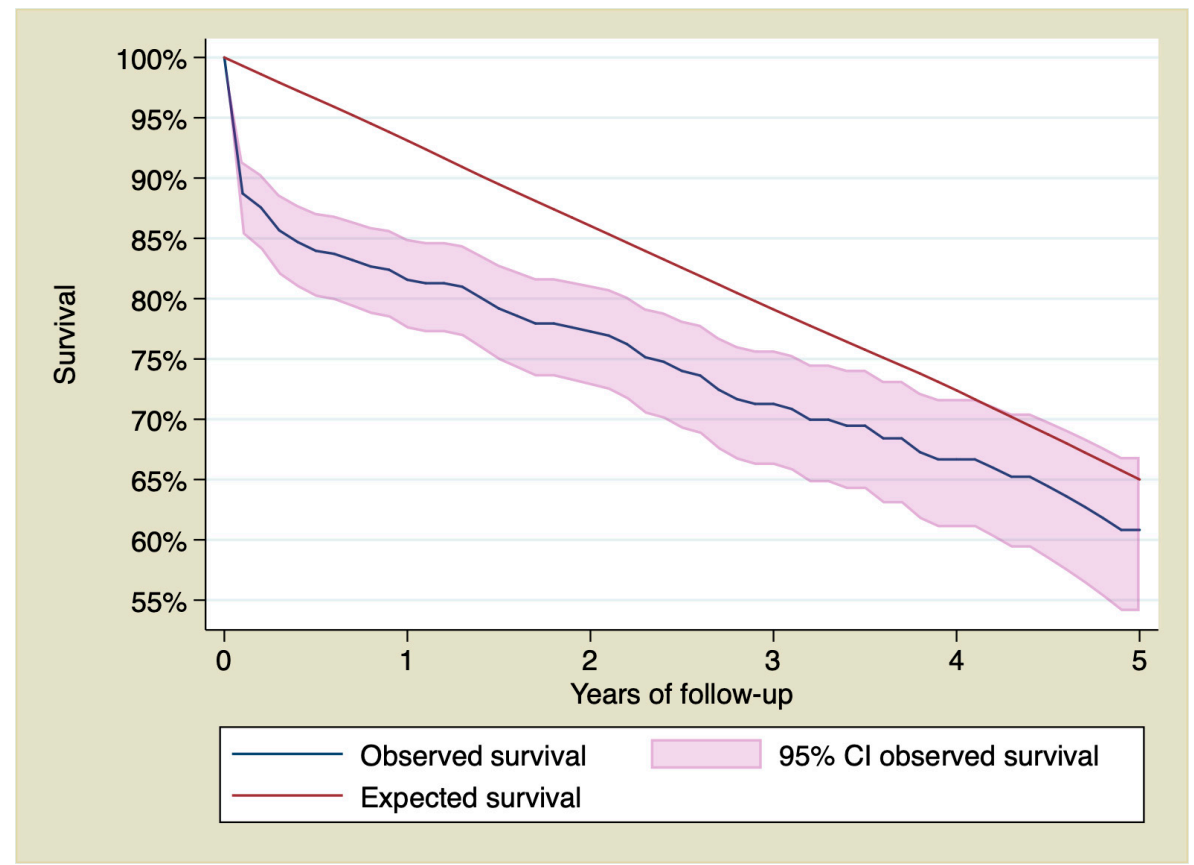

Figure 1. 95\% confidence interval of the observed survival compared with the expected survival of the sample. CI: Confidence Interval

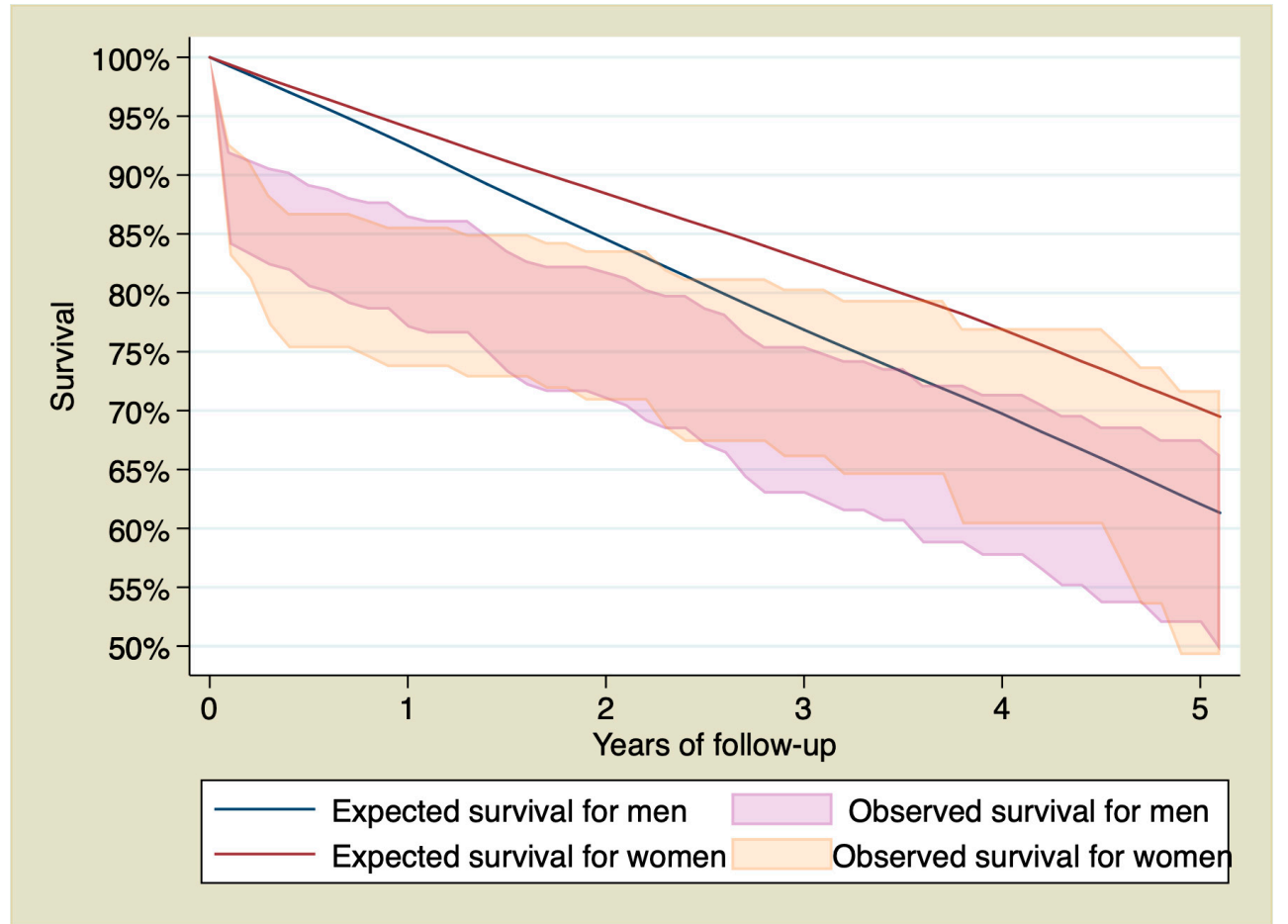

Figure 2. 95\% confidence interval of the observed survival compared with the expected survival of the sample stratified by sex.

RS in men calculated by annual intervals showed an excess of mortality due to the STEMI only during the first year of follow-up with a RS = 88.06\% (IC 95\% 82.15-92.73), indicating an excess of mortality of $11.94 \%$. However, after that year, RS did not show an excess of mortality due to the STEMI. That means that observed and expected survival were similar. RS in women calculated by annual intervals showed an excess of mortality during the first year higher than the observed in men, with a 
RS $=83.89 \%$ (CI 95\% 76.31-89.75) indicating an excess of mortality due to the STEMI of $16.11 \%$. In the following years, there were no differences in excess of mortality due to the acute event either. RS by year of follow-up is shown in Figure 3. Table 4 shows observed and expected survival and RS stratified by sex and calculated by the year of follow-up.

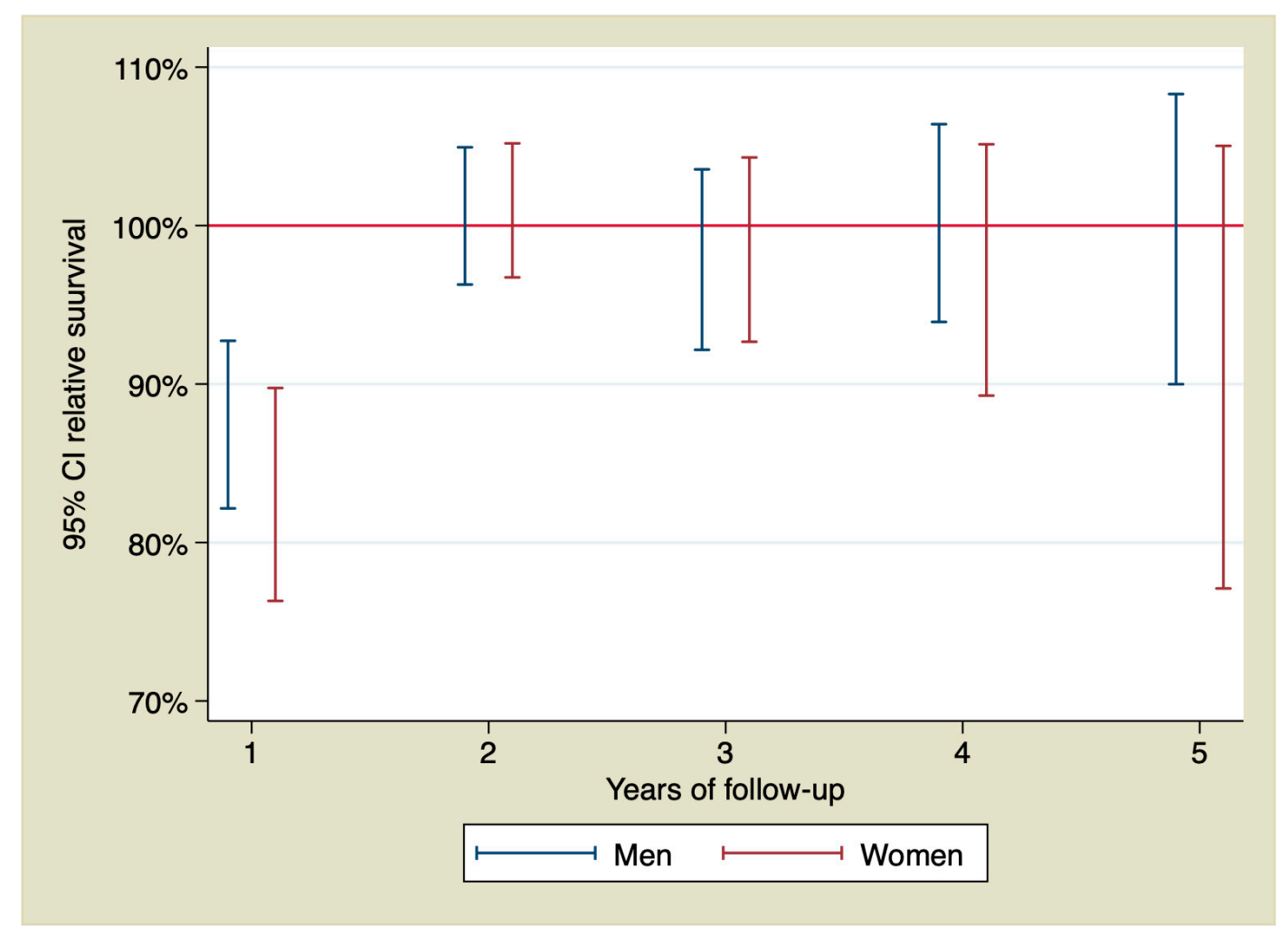

Figure 3. Relative survival by year of follow-up and stratified by sex.

Table 4. Observed and expected survival during the follow-up stratified by sex and calculated by year of follow-up. Relative survival by annual intervals were also calculated. CI: Confidence Interval; STEMI: ST elevation myocardial infarction.

\begin{tabular}{|c|c|c|c|}
\hline $\begin{array}{c}\text { Year of } \\
\text { Follow-Up }\end{array}$ & $\begin{array}{l}\text { Cumulative Survival of } \\
\text { Patients with STEMI } \\
\text { (Observed Survival) }\end{array}$ & $\begin{array}{l}\text { Cumulative Survival in } \\
\text { the Reference Group } \\
\text { (Expected Survival) }\end{array}$ & Annual Relative Survival * \\
\hline \multicolumn{4}{|l|}{ Men } \\
\hline First Year & $82.39 \%$ (CI 95\% 77.05-86.59) & $92.51 \%$ & $88.06 \%$ (CI 95\% 82.15-92.73) \\
\hline Second Year & $76.93 \%$ (CI 95\% 70.96-81.83) & $84.55 \%$ & $101.77 \%$ (CI 95\% 96.28-104.94) \\
\hline Third Year & $69.71 \%$ (CI 95\% 62.95-75.48\%) & $76.86 \%$ & $99.27 \%$ (CI 95\% 92.16-103.55) \\
\hline Fourth Year & $65.03 \%($ CI $95 \% 57.67-71.43)$ & $69.74 \%$ & $102.37 \%$ (CI 95\% 93.92-106.4) \\
\hline Fifth Year & $60.26 \%$ (CI 95\% 51.97-67.58\%) & $62.06 \%$ & $102.96 \%$ (CI 95\% 89.99-108.3) \\
\hline \multicolumn{4}{|l|}{ Women } \\
\hline First Year & $80.44 \%$ (CI 95\% 73.60-85.62) & $94.06 \%$ & $83.89 \%$ (CI 95\% 76.31-89.75) \\
\hline Second Year & $78.01 \%$ (CI 95\% 70.85-83.62) & $88.43 \%$ & $103.06 \%$ (CI 95\% 96.73-105.19) \\
\hline Third Year & 74\% (CI 95\% 66.04-80.37) & $82.81 \%$ & $100.99 \%$ (CI 95\% 92.67-104.3) \\
\hline Fourth Year & $69.54 \%$ (CI 95\% 60.34-77.01) & $77.56 \%$ & $101.02 \%$ (CI 95\% 89.27-105.13) \\
\hline Fifth Year & $61.57 \%$ (CI 95\% 49.24-71.74) & $70.27 \%$ & $97.41 \%$ (CI 95\% 77.10-105.03) \\
\hline
\end{tabular}

* Relative survival calculated by interval. This is not a cumulative estimation. 
3.4. Observed Survival, Expected Survival, and Relative Survival for Patients Who Were Discharged from the Hospital and Were Alive 30 Days after the STEMI

Cumulative survival at 1,3, and 5 years of follow-up for patients who suffered a STEMI and survived the first 30 days was $91.22 \%$ (CI 95\% 87.80-93.72), 79.71\% (CI 95\% 74.58-83.92), and 68.02\% (CI 95\% 60.66-74.3), whereas in the reference population it is $93.11 \%, 79.10 \%$, and $65.01 \%$, respectively. Figure 4 shows the survival of the STEMI group compared with the general population for patients who survived the first 30 days.

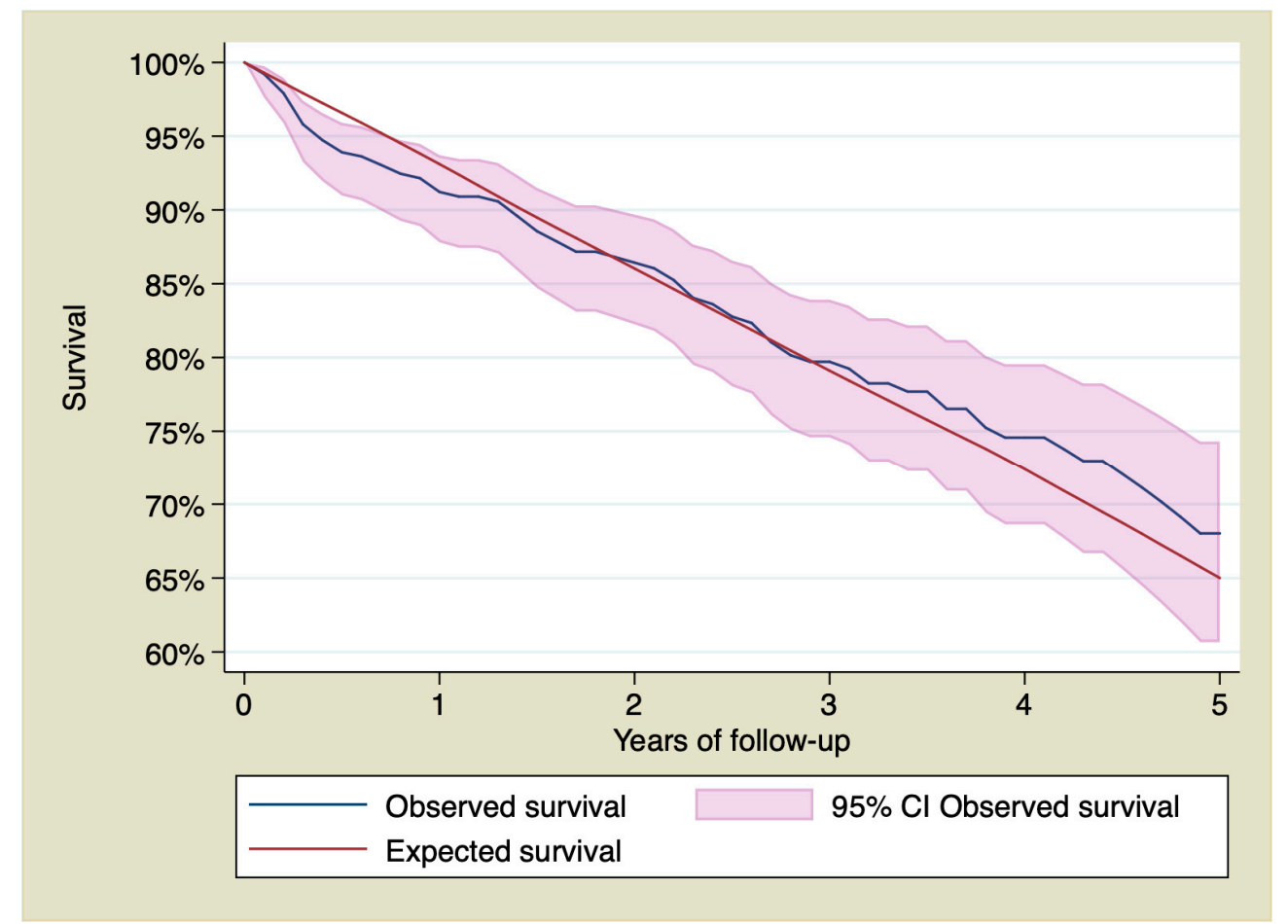

Figure 4. 95\% confidence interval of the observed survival compared with the expected survival. Only patients who survived the first 30 days after the ST elevation myocardial infarction.

Stratifying by sex, survival of men with STEMI at 1, 3, and 5 years of follow-up was $91.70 \%$ (CI 95\% 87.14-94.69), 77.59\% (CI 95\% 70.64-83.09), and 67.07\% (CI 95\% 58.06-74.57), whereas in the reference population it was $92.51 \%, 76.86 \%$, and $62.07 \%$. Survival in women with STEMI was $90.59 \%$ (IC $95 \%$ 84.59-94.33), 83.33\% (IC 95\% 75.23-88.98), and 69.34\% (IC 95\% 55.30-79.75) whereas in the reference population it was $94.05 \%, 82.81 \%$, and $70.16 \%$. Figure 5 shows the survival curves of patients with STEMI who survived the first 30 days, stratified by sex and compared with the general population.

In men, RS of the first year did not show an excess of mortality due to the STEMI, RS $=98.65 \%$ (CI 95\% 93.71-101.90\%). However, RS of the first year in women did show an excess of mortality with a RS $=95.82 \%$ (CI 95\% 89.18-99.98). RS of both men and women showed that observed and expected survivals were similar after the first year. Table 5 shows observed and expected cumulative survival and RS stratified by sex and calculated by the year of follow-up. 


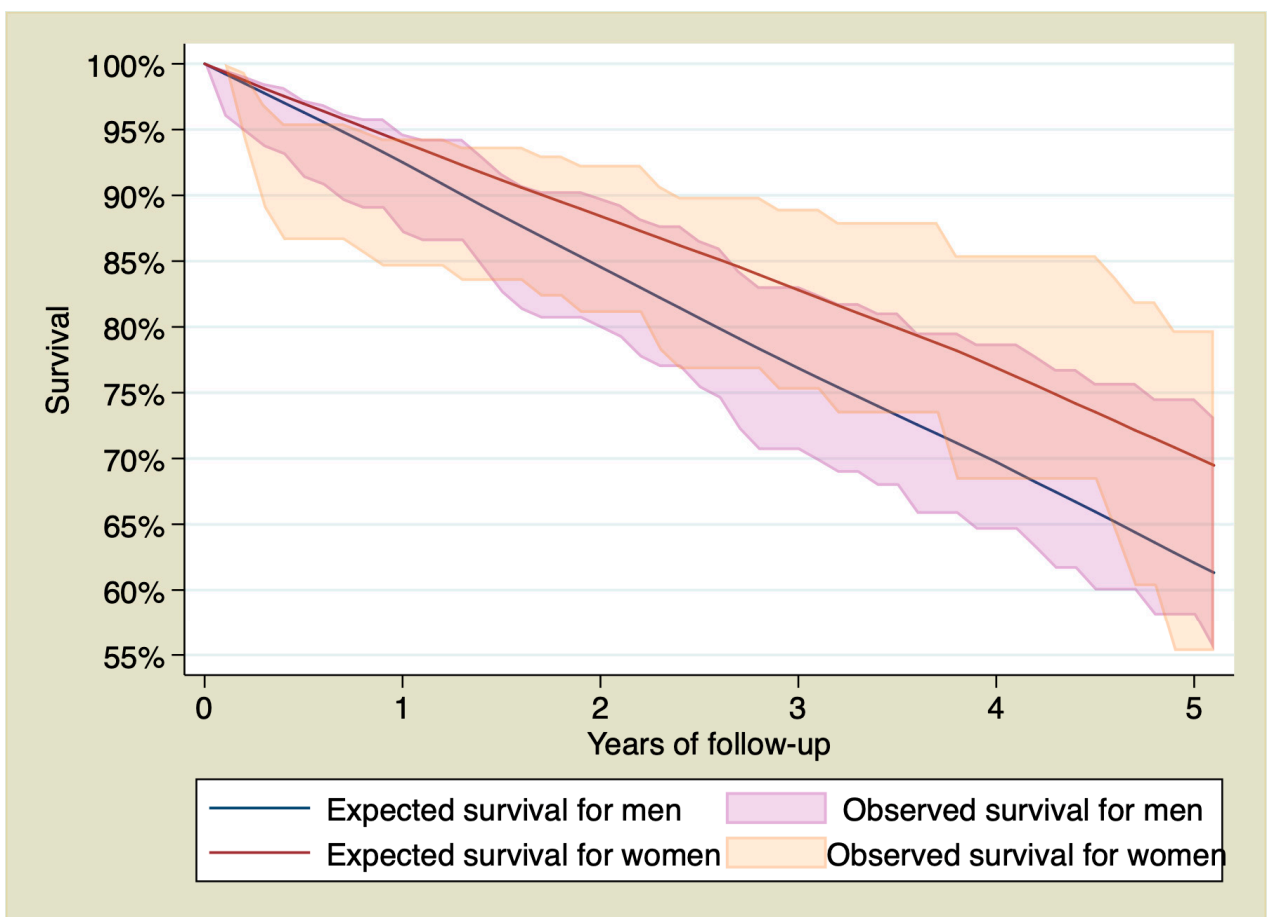

Figure 5. 95\% confidence interval of the observed survival compared with the expected survival. Only patients who survived the first 30 days after the ST elevation myocardial infarction, stratified by sex.

Table 5. Observed and expected survival during the follow-up stratified by sex and calculated by year of follow-up for patients who survived the first 30 days after the STEMI. Relative survival by annual intervals are also calculated.

\begin{tabular}{|c|c|c|c|}
\hline $\begin{array}{c}\text { Year of } \\
\text { Follow-Up }\end{array}$ & $\begin{array}{l}\text { Cumulative Survival of } \\
\text { Patients with STEMI } \\
\text { (Observed Survival) }\end{array}$ & $\begin{array}{l}\text { Cumulative Survival in } \\
\text { the Reference Population } \\
\text { (Expected Survival) }\end{array}$ & Annual Relative Survival * \\
\hline \multicolumn{4}{|l|}{ Men } \\
\hline First Year & 91.70\% (CI 95\% 87.14-94.69) & $92.51 \%$ & 98.65\% (CI 95\% 93.71-101.90) \\
\hline Second Year & $85.63 \%$ (CI 95\% 79.92-89.81) & $84.56 \%$ & 101.77\% (CI 95\% 96.28-104.94) \\
\hline Third Year & 77.59\% (CI 95\% 70.64-83.09) & $76.86 \%$ & 99.27\% (CI 95\% 92.16-103.55) \\
\hline Fourth Year & 72.38\% (CI 95\% 64.59-78.74) & $69.74 \%$ & 102.37\% (CI 95\% 93.92-106.4) \\
\hline Fifth Year & $67.07 \%$ (CI 95\% 58.06-74.57) & $62.07 \%$ & $102.96 \%$ (CI 95\% 89.99-108.3) \\
\hline \multicolumn{4}{|l|}{ Women } \\
\hline First Year & 90.59\% (CI 95\% 84.59-94.33) & $94.05 \%$, & 95.82\% (CI 95\% 89.18-99.98) \\
\hline Second Year & $87.85 \%$ (CI 95\% 81.07-92.32) & $88.42 \%$ & 103.06\% (CI 95\% 96.73-105.19) \\
\hline Third Year & $83.33 \%$ (CI 95\% 75.23-88.98) & $82.81 \%$ & 100.99\% (CI 95\% 92.67-104.3) \\
\hline Fourth Year & 78.31\% (CI 95\% 68.38-85.45) & $76.89 \%$ & $101.02 \%$ (CI 95\% 89.27-105.13) \\
\hline Fifth Year & $69.34 \%$ (CI 95\% 55.30-79.75) & $70.16 \%$ & $97.41 \%$ (CI 95\% 77.10-105.03) \\
\hline
\end{tabular}

* Relative survival calculated by interval. This is not a cumulative estimation.

\subsection{Influence of Sex on Long-Term Survival}

The influence of sex on late survival was assessed by a Cox regression analysis. Sex was not associated with late survival, $\mathrm{HR}=1.02$ (CI 95\% 0.67-1.53; $p=0.92$ ). The association of the other possible clinical and angiographic variables with late survival are described in Table 6. 
Table 6. Multivariable analysis.

\begin{tabular}{cccc}
\hline Variable & HR & 95\% Confidence Interval & $p$ \\
\hline Sex & 1.02 & $0.67-1.53$ & 0.920 \\
Age & 1.06 & $1.02-1.1$ & 0.004 \\
Diabetes & 0.93 & $0.63-1.38$ & 0.720 \\
Hypertension & 1.19 & $0.80-1.78$ & 0.390 \\
Dyslipidemia & 0.74 & $0.49-1.1$ & 0.140 \\
Smoking History & 1.23 & $0.81-1.88$ & 0.340 \\
Chronic Kidney Disease & 1.54 & $1.01-2.30$ & 0.046 \\
Previous Myocardial Infarction & 0.66 & $0.32-1.35$ & 0.250 \\
Previous Coronary Angioplasty & 1.19 & $0.53-2.71$ & 0.660 \\
Previous Coronary Artery Bypass Surgery & 2.34 & $0.98-5.74$ & 0.054 \\
Lesion on Anterior Descending Artery & 0.95 & $0.66-1.39$ & 0.800 \\
III or IV Killip Class & 5.14 & $3.41-7.75$ & $<0.001$ \\
Multivessel Diseas & 1.09 & $0.76-1.58$ & 0.630 \\
\hline
\end{tabular}

HR: Hazard Ratio.

\section{Discussion}

Primary PCI protocols in STEMI have widely demonstrated an improvement in clinical outcomes, including survival [1], particularly when performed in high-volume interventional centers $[29,30]$. In this context, the main finding of this study is the survival of those patients who were still alive 30 days after the MI. Remarkably, STEMI patients $>75$ years who underwent PCI in our center and survived the first 30 days, reached long-term survival similar to that of the general population. Our results highlight the importance of primary PCI strategies irrespective of age. Primary PCI in the elderly would let to recover their life expectancy. Interestingly, the first month after PCI seems a critical period in determining the prognosis.

Some studies have shown that female gender is an independent predictor for short-term mortality after primary PCI [31,32]. However, the possible influence of sex on long-term survival and is still unclear. The first month after primary PCI is a high-risk period, for both men and women. This high risk at the beginning makes the observed survival lower than the expected survival for both sexes during the first 3 years of follow-up. However, at a certain time between the third and fourth year of follow-up, the confidence interval of the observed survival curve begins to include the expected survival curve, indicating that both survivals are becoming similar. That means that STEMI patients $>75$ years old who underwent PCI at our center achieved long-term survival similar to that of the general population with the same age, sex, and geographical location from the third year onwards.

When analyzing differences between men and women from our cohort, we found some remarkable data. Men who survived the first 30 days after the STEMI completely recover their life expectancy, with both observed and expected survival curves similar from the beginning, as if they had never suffered the STEMI. This conclusion could be confirmed with the calculation of the RS. So, RS of the first year in men did not show an excess of mortality due to the STEMI. Conversely, women who survived the first 30 days were still at an increased risk of death during the first year, indicating that the risk of death in this group of patients is not limited to the first 30 days but is longer and more pronounced than that of the men. There were no significant differences in left ventricular ejection fraction that could explain these differences. Our data showed that, after this first year with high risk, women also achieved a survival similar to that of the general population during the rest of the follow-up.

Finally, despite women usually live longer in the general population, our data show that sex is not a risk factor for mortality in this group of patients. This is likely because women have a slightly higher risk of dying than men in the first 30 days of the follow-up. Probably, after having a STEMI, women cease to enjoy a greater long-term survival than men. 


\section{Limitations}

The present study has several limitations. Data were collected retrospectively. The results are only applicable to the studied population (STEMI patients $>75$ years old who underwent primary PCI in a single academic center). Caution should be taken when extrapolating these results. We did not have data on treatment throughout the follow-up period. In addition, sample size is relatively small and statistical power could be low.

\section{Conclusions}

Life expectancy of both men and women suffering a STEMI and treated with primary PCI is intimately linked to survival during the first period of time. Women who survive the first 30 days after the STEMI still have an excess of mortality due to the STEMI or its consequences during the first year of follow-up. This excess of mortality is not shown in men who survive the first 30 days. After one year, the risk of death for both men and women seems similar to that of the general population of the same age, sex, and geographical region. Sex is not a risk factor for long-term mortality in this group of patients.

Author Contributions: Conceptualization, I.P., R.D., J.S., and C.M.; data curation, M.A., R.L., and A.E.; formal analysis, A.E. and A.A.; investigation, D.H.-V., R.D. and A.A.; methodology, D.H.-V., R.L., and M.C.; supervision, J.S. and P.A.; validation, M.A.; writing-original draft, I.P. and D.H.-V.; writing-review and editing, C.M. and P.A. All authors have read and agreed to the published version of the manuscript.

Funding: This research received no external funding.

Conflicts of Interest: The authors declare no conflicts of interest.

\section{References}

1. Ibanez, B.; Stefan James, S.; Agewall, S.; Antunes, M.J.; Bucciarelli-Ducci, C.; Bueno, H.; Caforio, A.L.P.; Crea, F.; Goudevenos, J.A.; Halvorsen, S.; et al. 2017 ESC Guidelines for the management of acute myocardial infarction in patients presenting with ST-segment elevation. Eur. Heart J. 2018, 39, 119-177. [CrossRef]

2. Gale, C.P.; Allan, V.; Cattle, B.A.; Hall, A.S.; West, R.M.; Timmis, A.; Gray, H.H.; Deanfield, J.; Fox, K.A.A.; Feltbower, R. Trends in hospital treatments, including revascularization, following acute myocardial infarction, 2003-2010: A multilevel and relative survival analysis for the National Institute for Cardiovascular Outcomes Research (NICOR). Heart 2014, 100, 582-589. [CrossRef]

3. Pedersen, F.; Butrymovich, V.; Kelbæk, H.; Wachtell, K.; Helqvist, S.; Kastrup, J.; Holmvang, L.; Clemmensen, P.; Engstrøm, T.; Grande, P.; et al. Short- and Long-Term Cause of Death in Patients Treated With Primary PCI for STEMI. J. Am. Coll. Cardiol. 2014, 64, 2101-2108. [CrossRef]

4. Fokkema, M.L.; James, S.; Thorvinger, B.; Lagerqvist, B.; Albertsson, P.; Åkerblom, A.; Calais, F.; Eriksson, P.; Jensen, J.; Nilsson, T.; et al. Population Trends in Percutaneous Coronary Intervention: 20-year results from the SCAAR (Swedish Coronary Angiography and Angioplasty Registry). J. Am. Coll. Cardiol. 2013, 61, 1222-1230. [CrossRef]

5. Kochar, A.; Chen, A.Y.; Sharma, P.P.; Pagidipati, N.J.; Fonarow, G.C.; Cowper, P.A.; Roe, M.T.; Peterson, E.D.; Wang, T.Y. Long-Term Mortality of Older Patients With Acute Myocardial Infarction Treated in US Clinical Practice. J. Am. Heart Assoc. 2018, 7, e007230. [CrossRef]

6. Kontis, V.; Bennett,J.E.; Mathers, C.D.; Li, G.; Foreman, K.; Ezzati, M. Future life expectancy in 35 industrialized countries: projections with a Bayesian model ensemble. Lancet 2017, 389, 1323-1335. [CrossRef]

7. The EUGenMed; Cardiovascular Clinical Study Group; Regitz-Zagrosek, V.; Oertelt-Prigione, S.; Prescott, E.; Franconi, F.; Gerdts, E.; Foryst-Ludwig, A.; Maas, A.H.; Kautzky-Willer, A.; et al. Gender in cardiovascular diseases: Impact on clinical manifestations, management, and outcomes. Eur. Heart J. 2015, 37, 24-34. [CrossRef]

8. Brieger, D.; Eagle, K.A.; Goodman, S.G.; Steg, P.G.; Budaj, A.; White, K.; Montalescot, G. Acute Coronary Syndromes Without Chest Pain, An Underdiagnosed and Undertreated High-Risk Group: Insights from the Global Registry of Acute Coronary Events. Chest 2004, 126, 461-469. [CrossRef] [PubMed] 
9. Kaul, P.; Armstrong, P.W.; Sookram, S.; Leung, B.K.; Brass, N.; Welsh, R.C. Temporal trends in patient and treatment delay among men and women presenting with ST-elevation myocardial infarction. Am. Heart J. 2011, 161, 91-97. [CrossRef]

10. Diercks, D.B.; Owen, K.P.; Kontos, M.C.; Blomkalns, A.; Chen, A.Y.; Miller, C.; Wiviott, S.; Peterson, E.D. Gender differences in time to presentation for myocardial infarction before and after a national women's cardiovascular awareness campaign: A temporal analysis from the Can Rapid Risk Stratification of Unstable Angina Patients Suppress ADverse Outcomes with Early Implementation (CRUSADE) and the National Cardiovascular Data Registry Acute Coronary Treatment and Intervention Outcomes Network-Get with the Guidelines (NCDR ACTION Registry-GWTG). Am. Heart J. 2010, 160, 80-87. [CrossRef] [PubMed]

11. Vaccarino, V.; Parsons, L.; Peterson, E.D.; Rogers, W.J.; Kiefe, C.I.; Canto, J. Sex Differences in Mortality After Acute Myocardial Infarction: Changes from 1994 to 2006. Arch. Intern. Med. 2009, 169, 1767-1774. [CrossRef]

12. Vaccarino, V.; Parsons, L.; Every, N.R.; Barron, H.V.; Krumholz, H.M. Sex-Based Differences in Early Mortality after Myocardial Infarction. N. Engl. J. Med. 1999, 341, 217-225. [CrossRef]

13. Hvelplund, A.; Galatius, S.; Madsen, M.; Rasmussen, J.N.; Sand, N.P.; Tilsted, H.-H.; Thayssen, P.; Sindby, E.; Højbjerg, S.; Abildstrøm, S.Z. Women with acute coronary syndrome are less invasively examined and subsequently less treated than men. Eur. Heart J. 2009, 31, 684-690. [CrossRef]

14. Nguyen, J.T.; Berger, A.K.; Duval, S.; Luepker, R.V. Gender disparity in cardiac procedures and medication use for acute myocardial infarction. Am. Heart J. 2008, 155, 862-868. [CrossRef]

15. De Torbal, A.; Boersma, E.; Kors, J.A.; Van Herpen, G.; Deckers, J.W.; Van Der Kuip, D.A.; Stricker, B.H.; Hofman, A.; Witteman, J.C. Incidence of recognized and unrecognized myocardial infarction in men and women aged 55 and older: The Rotterdam Study. Eur. Heart J. 2006, 27, 729-736. [CrossRef]

16. Berger, J.S.; Elliott, L.; Gallup, D.; Roe, M.; Granger, C.B.; Armstrong, P.W.; Simes, R.J.; White, H.D.; Van De Werf, F.; Topol, E.J.; et al. Sex Differences in Mortality Following Acute Coronary Syndromes. JAMA 2009, 302, 874-882. [CrossRef]

17. Lichtman, J.H.; Wang, Y.; Jones, S.B.; Leifheit-Limson, E.C.; Shaw, L.J.; Vaccarino, V.; Rumsfeld, J.S.; Krumholz, H.M.; Curtis, J.P. Age and sex differences in inhospital complication rates and mortality after percutaneous coronary intervention procedures: Evidence from the NCDR ${ }^{\circledR}$. Am. Heart J. 2014, 167, $376-383$. [CrossRef]

18. Khera, S.; Kolte, D.; Gupta, T.; Subramanian, K.S.; Khanna, N.; Aronow, W.S.; Ahn, C.; Timmermans, R.J.; Cooper, H.A.; Fonarow, G.C.; et al. Temporal trends and sex differences in evascularization and outcomes of st-segment elevation myocardial infarction in younger adults in the United States. J. Am. Coll. Cardiol. 2015, 66, 1961-1972. [CrossRef]

19. Lawesson, S.S.; Alfredsson, J.; Fredrikson, M.; Swahn, E. A gender perspective on short- and long term mortality in ST-elevation myocardial infarction-A report from the SWEDEHEART register. Int. J. Cardiol. 2013, 168, 1041-1047. [CrossRef]

20. Heer, T.; Hochadel, M.; Schmidt, K.; Mehilli, J.; Zahn, R.; Kuck, K.; Hamm, C.; Böhm, M.; Ertl, G.; Hoffmeister, H.M.; et al. Sex Differences in Percutaneous Coronary Intervention-Insights From the Coronary Angiography and PCI Registry of the German Society of Cardiology. J. Am. Heart Assoc. 2017, 6, e004972. [CrossRef]

21. Berger, J.S.; Brown, D.L. Gender-Age Interaction in Early Mortality Following Primary Angioplasty for Acute Myocardial Infarction. Am. J. Cardiol. 2006, 98, 1140-1143. [CrossRef]

22. Pascual, I.; Hernandez-Vaquero, D.; Alperi, A.; Avanzas, P.; Díaz, R.; Moris, C.; Silva, J. Survival in elderly patients with transcatheter aortic valve implants compared with the general population. Rev. Esp. Cardiol. (Engl. Ed.) 2020. [CrossRef]

23. Hernandez-Vaquero, D.; Silva, J.; Escalera, A.; Álvarez-Cabo, R.; Morales, C.; Díaz, R.; Avanzas, P.; Moris, C.; Pascual, I. Life Expectancy after Surgery for Ascending Aortic Aneurysm. J. Clin. Med. 2020, 9, 615. [CrossRef]

24. Glaser, N.; Persson, M.; Jackson, V.; Holzmann, M.J.; Franco-Cereceda, A.; Sartipy, U. Loss in Life Expectancy After Surgical Aortic Valve Replacement: SWEDEHEART Study. J. Am. Coll. Cardiol. 2019, 74, 26-33. [CrossRef]

25. Dickman, P.; Coviello, E. Estimating and Modeling Relative Survival. Stata J. 2015, 15, 186-215. [CrossRef]

26. Hakulinen, T.; Seppä, K.; Lambert, P. Choosing the relative survival method for cancer survival estimation. Eur. J. Cancer 2011, 47, 2202-2210. [CrossRef] 
27. Instituto Nacional de Estadística. Tablas De Mortalidad Por Año, Provincias, Sexo, Edad Y Funciones. Available online: http://www.ine.es/jaxiT3/Tabla.htm?t=27154Consultadoel03deabrildel2019 (accessed on 18 April 2020).

28. Mariotto, A.B.; Noone, A.-M.; Howlader, N.; Cho, H.; Keel, G.E.; Garshell, J.; Woloshin, S.; Schwartz, L.M. Cancer Survival: An Overview of Measures, Uses, and Interpretation. JNCI Monogr. 2014, 2014, 145-186. [CrossRef]

29. West, R.M.; Cattle, B.A.; Bouyssie, M.; Squire, I.; De Belder, M.; Fox, K.A.; Boyle, R.; McLenachan, J.M.; Batin, P.D.; Greenwood, D.C.; et al. Impact of hospital proportion and volume on primary percutaneous coronary intervention performance in England and Wales. Eur. Heart J. 2010, 32, 706-711. [CrossRef]

30. Keeley, E.C.; Boura, J.A.; Grines, C.L. Primary angioplasty versus intravenous thrombolytic therapy for acute myocardial infarction: A quantitative review of 23 randomised trials. Lancet 2003, 361, 13-20. [CrossRef]

31. Cenko, E.; Yoon, J.; Van Der Schaar, M.; Badimón, L.; Bugiardini, R.; Kedev, S.; Stankovic, G.; Vasiljevic, Z.; Krljanac, G.; Kalpak, O.; et al. Sex Differences in Outcomes After STEMI: Effect Modification by Treatment Strategy and Age. JAMA Intern. Med. 2018, 178, 632. [CrossRef]

32. Venetsanos, D.; Lawesson, S.S.; Alfredsson, J.; Janzon, M.; Cequier, A.; Chettibi, M.; Goodman, S.G.; Hof, A.W.V.; Montalescot, G.; Swahn, E. Association between gender and short-term outcome in patients with ST elevation myocardial infraction participating in the international, prospective, randomised Administration of Ticagrelor in the catheterisation Laboratory or in the Ambulance for New ST elevation myocardial Infarction to open the Coronary artery (ATLANTIC) trial: A prespecified analysis. BMJ Open 2017, 7, e015241. [CrossRef]

(C) 2020 by the authors. Licensee MDPI, Basel, Switzerland. This article is an open access article distributed under the terms and conditions of the Creative Commons Attribution (CC BY) license (http://creativecommons.org/licenses/by/4.0/). 